\title{
Therapy-Related Malignant Neoplasm
}

National Cancer Institute

\section{Source}

National Cancer Institute. Therapy-Related Malignant Neoplasm. NCI Thesaurus. Code C4969.

The development of a malignant neoplasm in response to medical or surgical treatment, induced by the treatment itself. 